\title{
AISLAMIENTO DE ENTEROBACTERIAS EN ALGUNOS MOLUSCOS DEL MAR PERUANO.
}

\author{
Dora A. Taboada P. $\left({ }^{*}\right)$; Haydée Russac $\left({ }^{*}\right)$ y Carolina Ramos de Ormachea $\left({ }^{*}\right)$. \\ (*) Programa Académico de Biología. Universidad Particular Ricarda Palma. Lima, Perú. \\ (**) Departamento de Microbiología Entérica. Instituto Nocional de Salud. Lima, Perú.
}

S U M A R IO

En este trabojo se do a conocer el resultado de un estudio bacteriológico en 5 especies de moluscos que se utilizan en la alimentación humana, ellos fueron: Aulacomya ater, Gari sp., Mesodesma donacium, Aequipecten purpuratus y Thais chocoloto, obtenidos de diversos centros de expendio del Calloo y Lima.

Se aisló Salmonella enteritidis serotipo Derby y Edwardsiella de Gari sp. Otras bacterias como Proteus, Cirrobacter, Enterobacter y Serratia estuvieron presentes en los diversos moluscos. El $100 \%$ de ellos presentó contaminación por E. coli.

\section{S U M M A Y}

In this paper, it has given to know the result of a bacteriologic study on 5 species of mollusk used as human food, they were: Aulacomya ater, Gari sp., Mesodesma donacium, Aequipecten purpuratus and Thais chocolata; they were from several markets of Callao and Lima.

It was isolated Salmonella enteritidis serotype Derby and Edwardsiella of Gari sp. Others bacteria as Proteus, Citrobacter, Enterobacter and Serratia were presents too. All the mollusks were contamined by E. coli.

\section{INTRODUCCION}

Los mariscos, indudablemente, constituyen un alimento de elevado valor por su alto contenido en principios nutritivos ya que son fuente de proteínas, vitaminas y sales minerales indispensables en la dieta diaria. Por ejemplo: el consumo de Aulacomya ater "choro", Mesodesma donacium "machas" y Aequipecten purpuratus "concha de abanico", suministran 14.75 grs $\%, 27.10$ grs. $\%$ y 13.75 grs. \% de proteínas, respectivamente. Aimendras (1957).

También ha sido estimado que el consumo de "caracol negro", Thais chocolata, proporciona 19.60 grs. \% de proteínas y 6,120 U.l. de vitamina $A$ por gramo de grasa. Okuyama (1953).

Teniendo en cuenta que ellos son ingeridos crudos o sometidos a un ligero cocmiento, incluyendo el tracto digestivo, es indispensable que la calidad sanitaria sea tal que no afecte la salud del individuo ya que ellos pueden ser vectores de agentes patógenos, si consideramos que: a) Algunas especies crecen en lugares que podrian recibir aguas negras. Malnati (1973);

b) Por su transporte y manipuleo hasta los centros de expendio quedan expuestos a contaminaciones. Sevillano (1972);

c) Tienen diferentes hábitos alimenticios, algunos se alimentan por filtración.

Se sabe que, debido a la ingestión de mariscos crudos (ostras) procedentes de aguas contaminadas, se produjeron brotes epidémicos de fiebre tifoidea (RodríguezCastro y col. 1968). El presente trabajo tiene como objetivo determinar la contaminación por enterobacterias como Escherichia coli, el cual es considerado como un importante indicador de contaminación fecal; teniendo en cuenta que la presencia de este microorganismo podría significar la contaminación por entéricos patógenos como Salmonella, se realizó la identificación mediante pruebas bioquímicas de todos los organismos aislados $y$, además, pruebas serológicas en el caso de Salmonella.

Parte de una tesis oprobodo paro optar el grodo Académico de Bachiller en Biología en la Universidod Porticular Ricardo Palmo. 


\section{MATERIAL Y METODOS}

La muestra.-Se estudiaron moluscos de las siguientes especies:

100 ejemplares de Aulacomya ater (Molina, 1782) "choro", de los cuales 25 se obtuvieron del Terminal Pesquero del Callao y los 75 restantes del Mercado Central de Lima.

100 ejemplares de Gari sp. "almeja", siendo 25 de ellos procedentes del Terminal Pesquero del Callao y 75 del Mercado Central de Lima.

100 ejemplares de Mesodesma donacium (Lamarck, 1818), todos procedentes del Mercado Central de Lima.

100 ejemplares de Aequipecten purpuratus (Lamark) "concha de abanico", de los cuales 25 procedían del Terminal Pesquero del Callao y 75 del Mercado Central de Lima.

100 ejemplares de Thais chocolata (Duclos, 1832), "caracol negro", 25 adquiridos del Terminal Pesquero del Callao y los 75 restantes del Mercado Central de Lima.

100 ejemplares más de Gari sp. en los cuales se aplicaron métodos recomendados para el aislamiento de Salmonella en alimentos y que fueron adquiridos de los siguientes centros de consumo: Mercado Central de Lima, Mercado Mayorista de La Victoria, Terminal Pesquero del Callao y puesto ambulante de expendio de mariscos en La Victoria. El procesamiento de estos moluscos se realizó en el Departamento de Microbiología Entérica del Instituto Nacional de Salud.

Recolección de la muestra.- Se hizo entre las 8 y 9 de la mañana, protegiéndolos al maximo del medio externo, para lo cual fue necesario usar bolsas de polietileno. El traslado al laboratorio demoró alrededor de 1 hora.

Estudio de la muestra.-Observación macroscópica: Los mariscos presentaron aspecto uniforme, olor característico y por sus movimientos se pudo evidenciar su estado de frescura (vivos).

\section{ESTUDIO BACTERIOLOGICO}

Procedimiento técnico.-Cada ejem- plar fue considerado como una muestra En condiciones asépticas se realizó la extracción del contenido de cada marisco en placas de Petri o mortero estériles, utilizando material de disección estéril. El proceso seguido fue el siguiente:

1. Pre-enriquecimiento. Que se hizo con la finalidad de obtener una mayor proliferación de los probables gérmenes patógenos existentes en cada muestra, utilizando como medios de cultivo Caldo Nutritivo Difco y Agua de Peptona (Triptona No. 3 al $2 \%$ ) incubados durante 24 hrs. a $37^{\circ} \mathrm{C}$. A partir de este proceso se realizó el plaqueo en los siguientes medios de cultivo selectivos: Agar Mac Conkey Difco y para las 100 últimas muestras de Gari sp., Agar Tergitol. Las colonias obtenidas de estas placas fueron estudiadas en medios diferenciales (Ver No. 4).

2. En riquecimiento.. En los medios de cultivo Caldo Selenito Difco y Caldo Tetrationato $\mathrm{BBL}$, durante $24 \mathrm{hrs}$. a $37^{\circ} \mathrm{C}$.

3. Utilización de medios selectivos. El plaqueo a partir de los cultivos en caldo de enriquecimiento se realizó en los medios selectivos Agar Mac Conkey DifCo, Agar SS (Salmonella-Shigella) Difco, Agar Verde Brillante Difco. En las 100 últimas muestras se utilizaron los medios selectivos mencionados al final. La incubación fue por $24 \mathrm{hrs}$, a $37^{\circ} \mathrm{C}$.

4. Utilización de medios diferenciales. El repicaje de las colonias sospechosas y de algunos coliformes se realizó en los medios diferenciales presuntivos SMG (SH2, manitol y glucosa) de Colichón (1956); SLU (sacarosa, lactosa, úrea) del mismo autor. Los medios TSI (glucosa, lactosa, sacarosa y SH2) y LIA (lisina, SH2) fueron utilizados en el estudio de las 100 últimas muestras de Gari sp. en el Laboratorio de Microbiología Entérica del Instituto Nacional de Salud.

5. Esłudio bioquímico. Se utilizaron en forma individual: glucosa, lactosa, sacarosa y manita; el primero con inclusión de tubos de Durham para evidenciar gas. Se utilizó el indicador de Andrade. Las lecturas se hicieron hasta el 30vo. día.

Aminoácidos: lisina, arginina, ornitina, fenilalanina. 
También fueron utilizados: malonato de sodio, citrato de Christensen, úrea de Christensen. La producción de indol fue evidenciada en el medio SIM Difco y agua de peptona. Además se utilizaron otras pruebas como KCN, MR-VP, reducción de nitratos y el test de oxidaciónfermentación.

6. Estudio serológico. Se llevó a cabo sólo para Salmonella y a partir de la cepa cultivada en medio Agar Infusión a $37^{\circ} \mathrm{C}$ por 24 hrs., en el Centro de Referencia del Instituto Nacional de Salud.

\section{RESULTADOS}

De los 600 ejemplares de moluscos que se estudiaron, sólo una muestra reveló contaminación por el patógeno entérico Salmonella enteritidis serotipo Derby. La muestra correspondió a una de las 100 últimas de Gari sp. como se apreciará después. Sin embargo, el $100 \%$ de las muestras reveló contaminación fecal ya que, de todas, se aisló Escherichia coli, organismo indicador.

Otras de las Enterobacterias que se aisló fue Proteus en porcentajes que oscilan entre 65 y $100 \%$, según el molusco.

Aulacomya ater "choro" resultó ser el más contaminado entre todos los mariscos: de las 100 muestras, el $100 \%$ presentó E. coli, 100\% Proteus, 20\%
Klebsiella, $50 \%$ Enterobacter, $66 \% \mathrm{Ci}$ trobacter y $4 \%$ Serratia. Alcaligenes y Pseudomonas, gérmenes que no pertenecen a las Enterobacterias, se aislaron del 50 al $85 \%$ de las muestras, respectivamente. En el 15\% de las muestras de A. ater se logró aislar todos estos gérmenes.

Mesodesma donacium "macha", es otro marisco que fue capaz de contener una gran variedad de bacterias; asi, de las 100 muestras, el $100 \%$ presentó $\mathbf{E}$. coli, $80 \%$ Proteus, $50 \%$ Enterobacter, $50 \%$ Citrobacter, $33 \%$ Alcaligenes y $100 \%$ Pseudomonas.

En Thais chocolata "caracol negro", de 100 muestras, $100 \%$ presentó E. coli, $72 \%$ Proteus y $100 \%$ Pseudomonas.

Aequipecten purpuratus "concha de abanico" presentó, de 100 muestras, el $100 \%$ E. coli, $60 \%$ Citrobacter, $65 \%$ Proteus y $20 \%$ Enterobacter; también se observó contaminación por Alcaligenes en el $32 \%$ y por Pseudomonas en el $100 \%$.

En las 100 primeras muestras de Gari sp., el 100\% tuvo E. coli, $90 \%$ Proteus, $53 \%$ Citrobacter, $38 \%$ Enterobacter, 12 $\%$ Klebsiella, $2 \%$ Serratia, $30 \%$ Alcaligenes y $100 \%$ Pseudomonas. Todos estos datos se encuentran sumarizados en la TABLA ?.

TABLA 1

CONTENIDO BACTERIANO EN 5 ESPECIES DE MOLUSCOS ESTUDIADOS

( 100 muestras de cada especie).

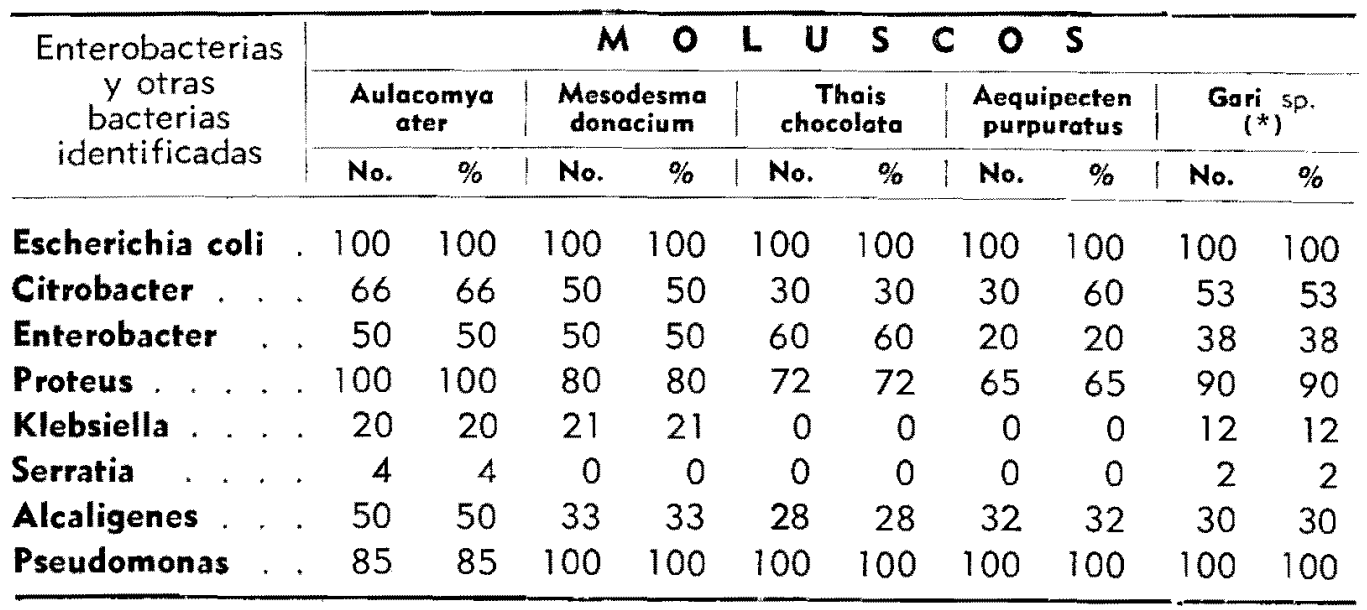

(*) Corresponde a las 100 primeras muestras. 
Al investigar las 100 últimas muestras de Gari sp., se obtuvo el 1\% contaminada con una cepa de Salmonella enteritidis serotipo Derby, esta muestra era procedente del mercado; de acuerdo a la jiteratura consultada, éste es el primer hallazgo de esta bacteria en Gari sp.

También se observó, en el $100 \%$, la presencia de E. coli; en el $84 \%$, Proteus; en el $4 \%$, Enterobacter; en el $2 \%$, Serratia; y en el $4 \%$, Edwarsiella ( 4 cepas de 4 muestras). TABLA 2.

TABLA 2

ENTEROBACTERIAS AISLADAS EN 100 MUESTRAS DE GARI SP.

\begin{tabular}{|c|c|c|c|}
\hline \multirow{2}{*}{\multicolumn{2}{|c|}{ Enterobacterias }} & \multicolumn{2}{|c|}{ Muestras contaminadas } \\
\hline & & No. & $\%$ \\
\hline Escherichia coli & . . & 100 & 100 \\
\hline Proteus . . . . . . & . . & 84 & 84 \\
\hline Citrobacter . . . . & . . & 26 & 26 \\
\hline Enterobacter . . . & . & 4 & 4 \\
\hline Serratia . . . . . & $\therefore$ & 2 & 2 \\
\hline Edwardsiella . . . . & . . & 4 & 4 \\
\hline Salmonella . . . . . . & . . & 1 & 1 \\
\hline
\end{tabular}

\section{DISCUSION}

Al investigar las muestras propuestas, se aisió una cepa de Salmonella enteritidis serotipo Derby de una $(1 \%)$ muestra correspondiente a las 100 últimas de Gari sp. Si tomamos el número total de muestras $(600)$, el porcentaje sería de $0.16 \%$. (TABLA 2). En la TABLA 1 se muestran las bacterias entéricas identificadas como Proteus, Citrobacter, Enterobacter, Klebsiella, Serratia, Edwardsiella y Escherichia coli. Los tres primeros géneros pueden ser contaminantes del polvo y el último, contaminante fecal.

Con respecto a Edwardsiella, al igual que E. coli, su presencia en Gari sp. no había sido aún referida en la literatura. Aún cuando los microorganismos, primeramente mencionados, no son considerados patógenos, en determinadas condiciones producen transtornos intestinales tanto en humanos como en animales.
Se han encontrado también Pseudomonas en el $100 \%$ de las muestras estudiadas y Alcaligenes en diversos porcentajes, según el molusco; estos gérmenes no corresponden a las Enterobacterias, el primero de los cuales pertenece a organismos marinos (Caria y Casellas, 1971); Casellas y col., 1971), que, al igual que los anteriormente mencionados, son retenidos en las cavidades de los moluscos, lo que explica su alta incidencia. Gari sp. resultó ser el más contaminado con entéricos; por el contrario, Thais chocolata y Aequipecten purpuratus presentaron menos especies de Enterobacterias. Sin embargo, el 100\% de ellos presentó Pseudomonas.

Con referencia a Aulacomya ater "choro", nosotros no encontramos Salmonella, coincidiendo con Sevillano (1972); en cambio, Hoces (1966) refiere su hallazgo en el $92 \%$ de sus muestras estudiadas, esto podría deberse al habitat de los moluscos próximos a desagües. 
Uehara (1968) dio a conocer el hallazgo de Salmonella en Aequipecten purpuratus "concha de abanico" en el $5 \%$ de sus muestras, en cambio nosotros, en el mismo molusco, no hemos aislado este microorganismo. Los serotipos de Salmonella no han sido indicados por Hoces ni Uehara.

La presencia de E. coli confirma el grado de contaminación fecal al que se encuentran sometidos algunos moluscos utilizados en la alimentación humana y su constancia en las muestras estudiadas hace que el riesgo de contaminación por patózenos entéricos sea elevado. Rodriguez-Castro y col. (1968).

Durante la recolección de las muestras se comprobó que los moluscos eran colocados en sacos semejantes a redes sobre el piso siempre húmedo y con barro de color negro, por donde circula el agua libremente; también se constató que, algunas veces, estos moluscos fueron depositados en el suelo sin ninguna protección, por lo que pensamos que estos centros de distribución constituyen importantes focos de contaminación fecal ya que, una vez implantados los gérmenes entéricos en los moluscos, pueden permanecer viables aún a temperaturas de refrigeración, convirtiéndose estos últimos en peligrosos vectores. Digirolamo y col. (1971).

Debemos indicar que las muestras estudiadas no presentaron signos externos de descomposición a pesar de haberse detectado microorganismos que se aislan de alimentos descompuestos.

\section{REFERENCIAS BIBLIOGRAFICAS}

ALMENDRAS, Ch., A. - 1957. Determinación del Triptofano, Arginina y Fenilalanina en proteinas de moluscos de la costa peruana. Tesis Bach. Formacia y Bioquímica, UNMSM. 67 pp.

CARIA, M. A., y CASELLAS, J. M. - 1971 Bocterias marinas heterotrofas aerobias aisladas del mar argentino. I. Distribución y grupos fisiológicos. Rev. Asoc. Arg. Microbiol. 3: $36-45$.

CASELLAS, J. M. CARIA, M. A. y MURTAGH, M. - 1971. Bacterios morinos heterotrofos oeroblas aislodas del mor argentino. II. Taxonomí y nutrición. Ibid. 3:46-57.

DIGIROLAMO, R, LISTON, J. y MATCHES, J. R. - 1971. Efectos de la congeloción en la sobrevivencia de Salmonella derby, S. typhimurium y E. coli en ostras del Pocifico. J. Food. Sci. $35: 1-16$

HOCES, A. S. G. - 1966. Saimonellas en choros (Mytilus magallanicus). Tesis Bach. Oceanografía y Pesqueria, Univ. Federico Villarreal. Limo, 27 pp.

MALNATI, F. L. - 1973. La polución acuática y sus efectos en la piscicultura. Simposio: EI Desarrollo de lo Pisciculturo en el Perú. Lima, Perú.

OKUYAMA, B. Victoria - 1953. Contribución al estudio bacteriológico de Thais chocolata "caracol negro". Tesis Bach. Formacio y Bioquímica. UNMSM. $21 \mathrm{pp}$.

RODRIGUEZ-CASTRO, R. y FERNANDEZ, E. E. 1968. Estudio bacteriológico de lo colidad sanitaria de los ostiones consumidos en la ciudad de México. Rev. Latín. Amer. Microbiol. Parasitol. 10:53-106.

SEVILLANO, E. Elsa - 1972. Análisis comporotivo de la flora microbiana patógena en choras crudos y procesados en cebiche. Tesis Boch. Ciencias Biológicos, UNMSM.

UEHARA, U. J. A. - 1968. Investigoción del grupo Salmonella y gérmenes testigos de contaminación fecal en "concho de abanico" (Aequipecten purpuratus). Tesis Boch. Oceno" grafio y Pesquería, Univ. Federico Villarreal. Limo, Perú 